\title{
Hemoglobin A2 Prime to Total Hemoglobin Ratio Measurement
}

National Cancer Institute

\section{Source}

National Cancer Institute. Hemoglobin A2 Prime to Total Hemoglobin Ratio

Measurement. NCI Thesaurus. Code C147353.

The determination of the ratio of hemoglobin A2 prime compared to total hemoglobin present in a sample. The measurement may be expressed as a ratio or percentage. 